\title{
Scientometrics of anesthetic drugs and their techniques of administration, | 984-20I3
}

This article was published in the following Dove Press journal:

Drug Design, Development and Therapy

9 December 2014

Number of times this article has been viewed

\section{Kamen V Vlassakov \\ Igor Kissin}

Department of Anesthesiology, Perioperative and Pain Medicine, Brigham and Women's Hospital, Harvard Medical School, Boston, MA, USA
Correspondence: Igor Kissin Department of Anesthesiology, Brigham and Women's Hospital, 75 Francis Street, Boston,

MA 02115, USA

Tel +I 6177325052

Fax+l 6177340682

Email kissin@zeus.bwh.harvard.edu
Abstract: The aim of this study was to assess progress in the field of anesthetic drugs over the past 30 years using scientometric indices: popularity indices (general and specific), representing the proportion of articles on a drug relative to all articles in the field of anesthetics (general index) or the subfield of a specific class of anesthetics (specific index); index of change, representing the degree of growth in publications on a topic from one period to the next; index of expectations, representing the ratio of the number of articles on a topic in the top 20 journals relative to the number of articles in all $(>5,000)$ biomedical journals covered by PubMed; and index of ultimate success, representing a publication outcome when a new drug takes the place of a common drug previously used for the same purpose. Publications on 58 topics were assessed during six 5-year periods from 1984 to 2013. Our analysis showed that during 2009-2013, out of seven anesthetics with a high general popularity index ( $\geq 2.0)$, only two were introduced after 1980, ie, the inhaled anesthetic sevoflurane and the local anesthetic ropivacaine; however, only sevoflurane had a high index of expectations (12.1). Among anesthetic adjuncts, in 2009-2013, only one agent, sugammadex, had both an extremely high index of change $(>100)$ and a high index of expectations (25.0), reflecting the novelty of its mechanism of action. The index of ultimate success was positive with three anesthetics, ie, lidocaine, isoflurane, and propofol, all of which were introduced much longer than 30 years ago. For the past 30 years, there were no new anesthetics that have produced changes in scientometric indices indicating real progress.

Keywords: anesthetics, anesthetic adjuvants, mortality, safety margins, therapeutic indices

\section{Introduction}

Scientometrics is devoted to the measurement of scientific output (publications) as well as of the impact of scientific findings on subsequent developments in related areas of research. This study evaluated the evolution of different anesthetics and techniques of their administration over the past 4 decades using a number of new scientometric indices. ${ }^{1-6}$

In the course of this evaluation, our interests were centered on various developments related to the use of anesthetic drugs, including the dramatic decrease in anesthesiarelated mortality. Over the past 4 decades, many changes in drugs used for anesthesia may have contributed to this decrease. In 1954, Beecher and Todd published a study on mortality during the perioperative period, based on 599,548 cases collected from ten academic hospitals over 6 years. ${ }^{7}$ They found that anesthesia was a primary or contributory cause of mortality in one per 1,560 cases. Several studies that followed (1956-1975) reported comparable rates of mortality. ${ }^{8-11}$ Presently, the risk related to anesthesia is estimated to be approximately ten times lower. ${ }^{12}$ The strong impact of anesthetics on mortality stems from their low margins of safety. As indicated in Goodman and Gilman's Pharmacological Basis of Therapeutics, "the inhalational 
anesthetics have therapeutic indices (median lethal dose/ median effective dose $\left.\left[\mathrm{LD}_{50} / \mathrm{ED}_{50}\right]\right)$ that range from 2 to 4 , making these among the most dangerous drugs in clinical use". ${ }^{13}$ For example, the experimentally determined (in rats) therapeutic index $\left(\mathrm{LD}_{50} / \mathrm{ED}_{50}\right)$ of halothane for motor responses is $4.1 .{ }^{14}$ Over the past 4 decades, many changes in drugs used for anesthesia may have contributed to the dramatic decrease in mortality and morbidity.

Scientometric assessments of various classes of drugs have been reported in a number of publications. ${ }^{1-6}$ Some of the scientometric indices can be used to indicate certain changes in drug administration..$^{3,5,6}$ The main aim of this study was to find signs of progress in the use of anesthetics over the period 1984-2013.

\section{Methods}

The following scientometric parameters ${ }^{4-6}$ were used as signs of progress in assessment of anesthetics.

\section{General popularity index}

The general popularity index (GPI) is the percentage of articles on a specific anesthetic among all articles on anesthetics (Anesthetics [MeSH term]) published over the same 5-year period. A specific threshold of $0.1 \%$ for 2009-2013 (arbitrary) was used to select topics for which the number of publications reached a notable level.

\section{Specific popularity index}

The specific popularity index (SPI) is the number of articles on a specific anesthetic used to provide one of the following types of anesthesia: inhalational anesthesia (Anesthesia, Inhalation $[\mathrm{MeSH}$ term]), intravenous anesthesia (Anesthesia, Intravenous [MeSH term]), or local anesthesia (Anesthesia, Local [MeSH term]), presented as a percentage of all articles on the appropriate type of anesthesia (for example, "Lidocaine AND Anesthesia, Local" as a percentage of all articles with term "Anesthesia, Local"). Publications were counted for each 5-year period starting with 1979-1983.

\section{Index of change}

The index of change (IC) is the percentage change in the number of publications on a drug or technique during a 5-year (or 10 -year) period compared with the previous similar period. It reflects the change in general interest in a topic. The specific threshold used for this index was $\geq 50$, ie, the growth beyond the increase (percent) in number of publications in the whole field of PubMed drug-related articles (Drug [MeSH term]) during the same time interval.

\section{Index of expectations}

The index of expectations (IE),or Top Journal Selectivity Index, is the ratio of the number of all types of articles on a particular topic in the top 20 journals relative to the number of articles in all $(>5,000)$ biomedical journals covered by PubMed over 5 years, reflecting the level of interest in the top journals. An index value $\geq 10$ was selected to represent a high expectation of success. The 20 top journals were selected based on two factors, ie, their rank sorted by impact factor, as indicated by Journal Citation Report for 2013, and the journal specialty area. They included pharmacology, anesthesia, pain, and surgery (ten journals), and general biomedical journals (also ten journals), as follows: Anesthesiology, Annals of Internal Medicine, Annals of Surgery, British Journal of Anaesthesia, British Journal of Surgery, British Medical Journal, Journal of American College of Surgeons, Journal of American Medical Association, Journal of Clinical Investigation, Journal of Clinical Pharmacology and Therapeutics, Journal of Pharmacology and Experimental Therapeutics, The Lancet, Nature, Nature Medicine, Nature Reviews Drug Discovery, New England Journal of Medicine, Pain, Proceedings of the National Academy of Science of the United States of America, Science, Trends in Pharmacological Sciences.

\section{Index of ultimate success}

Index of ultimate success (IUS) is a publication outcome indicating that a new drug (or group of drugs) has taken the place of a drug that had previously been commonly used for the same purpose. It is measured by the degree of decline in SPI of an old, supplanted drug. Decline in the SPI of a supplanted drug $\geq 50 \%$ during an interval of 10-20 years was selected to represent a positive IUS for the new drug.

The articles were counted using the National Library of Medicine's PubMed website (http://www.ncbi.nlm.nih.gov/ pubmed/) which covers over 21 million journal articles in biomedicine. Various individual anesthetic drug names or terms related to the techniques of their administration were entered in the search box. Filter for languages (English) was used. All types of articles were considered.

The criterion for selection of a particular drug for analysis was the level of its GPI in 2009-2013. If the GPI was $\geq 0.1$, the drug was also assessed using SPI. The IC and IE were determined if the following two criteria were satisfied: the last of the initial 100 articles on a topic was published after 1980 and the number of articles in 2009-2013 was $\geq 50$. IUS was calculated when a new drug caused a stable decline over 10-15 years in SPI of an alternative drug. 
The following categories of terms were included in the searches: anesthetics (inhaled, intravenous, and local); anesthetic adjuncts (all drugs that are used to modify the main effects of anesthetics, including analgesics, sedatives, neuromuscular blocking agents with antagonists, and alpha 2-selective adrenergic receptor agonists); and techniques used for anesthetic administration (methods of measuring the main anesthetic effect, ie, depth of sedation, are also included in this category).

The terms were selected from various sources. ${ }^{15-20}$ The following terms were searched: "alfentanil", "atracurium", "benzocaine", "bispectral index", "bupivacaine", "buprenorphine", "chloroprocaine", "cisatracurium", “clonidine", "closed-loop anesthesia", "combined spinal-epidural", "continuous epidural", "continuous nerve block", "continuous spinal", "desflurane", "dexamethasone", "dexmedetomidine", "diazepam”, “edrophonium”, "enflurane”, "entropy”, "etomidate", "fentanyl”, "gantacurium", "halothane", "isoflurane", "ketamine", "levobupivacaine”, "lidocaine”, "median electroencephalographic frequency", "mepivacaine", "methohexital”, “midazolam”, “mivacurium”, "morphine", "neostigmine", "nitrous oxide", "pancuronium", "prilocaine", "procaine", "propofol", "pyridostigmine", "remifentanil", "robotic anesthesia", "rocuronium", "ropivacaine", "sevoflurane", "spectral edge frequency", "succinylcholine", "sufentanil", "sugammadex", "target-controlled anesthesia", "tetracaine", "thiopental", "total intravenous anesthesia", "ultrasound-guided block", "vecuronium", "volatile induction", "wound infiltration", and "xenon".

\section{Results Anesthetics}

Table 1 indicates that, in 2009-2013, 19 anesthetics had a GPI $\geq 0.1$, comprising six inhaled, four intravenous, and nine local anesthetics. Of the four that were introduced after 1980, two are inhaled anesthetics (sevoflurane and desflurane) and the other two are local anesthetics (ropivacaine and levobupivacaine). Of the 19 anesthetics with a GPI $\geq 0.1$, seven were higher than 2.0, comprising isoflurane, nitrous oxide, and sevoflurane (among inhaled anesthetics), propofol (among intravenous anesthetics), and lidocaine, bupivacaine, and ropivacaine (among local anesthetics).

Table I Popularity indices (GPI and SPI) of anesthetics

\begin{tabular}{|c|c|c|c|c|c|c|c|c|}
\hline \multirow[t]{2}{*}{ Name } & \multirow[t]{2}{*}{ Introduction ${ }^{a}$} & \multirow{2}{*}{$\begin{array}{l}\text { Number of articles } \\
(2009-2013)\end{array}$} & \multirow{2}{*}{$\begin{array}{l}\text { GPI (\%) } \\
(2009-2013)\end{array}$} & \multicolumn{5}{|l|}{ SPI (\%) } \\
\hline & & & & |989-1993 & | $994-1998$ & 1999-2003 & 2004-2008 & 2009-2013 \\
\hline \multicolumn{9}{|c|}{ Inhaled anesthetics } \\
\hline Isoflurane & 1971 & 2,048 & 4.5 & 28.7 & 35.2 & 31.3 & 30.6 & 28.4 \\
\hline Nitrous oxide & 1844 & $\mathrm{I}, 836$ & 4.0 & 26.2 & 23.5 & 20.9 & 15.3 & 11.8 \\
\hline Sevoflurane & 1987 & 1,666 & 3.7 & 3.2 & 14.8 & 27.0 & 30.8 & 32.6 \\
\hline Halothane & 1956 & 406 & 0.9 & 28.8 & 23.6 & 15.9 & 8.8 & 3.6 \\
\hline Desflurane & 1990 & 402 & 0.9 & 3.6 & 9.2 & 6.7 & 9.3 & 7.8 \\
\hline Enflurane & 1968 & 53 & 0.1 & 10.3 & 6.4 & 2.4 & 1.2 & 0.5 \\
\hline \multicolumn{9}{|c|}{ Intravenous anesthetics } \\
\hline Propofol & 1977 & 3,957 & 8.7 & 19.0 & 24.5 & 34.7 & 36.9 & 34.9 \\
\hline Thiopental & 1934 & 399 & 0.9 & 9.6 & 8.9 & 5.7 & 4.2 & 2.5 \\
\hline Etomidate & 1973 & 386 & 0.8 & 2.2 & 2.1 & 2.0 & 2.3 & 2.0 \\
\hline Methohexital & 1960 & 37 & 0.1 & 2.2 & 1.8 & 1.4 & 0.6 & 0.4 \\
\hline \multicolumn{9}{|c|}{ Local anesthetics } \\
\hline Lidocaine & 1947 & 3,667 & 8.1 & 22.8 & 25.3 & 22.4 & 19.8 & 17.5 \\
\hline Bupivacaine & 1963 & 2,230 & 4.9 & $\mathrm{I} \mid .3$ & 18.1 & 18.2 & 16.6 & 14.4 \\
\hline Ropivacaine & $1996^{d}$ & 936 & 2.1 & 1.2 & 1.4 & 7.1 & 6.9 & 5.9 \\
\hline Levobupivacaine & 1995 & 379 & 0.8 & - & - & 1.3 & 3.3 & 3.4 \\
\hline Procaine & 1905 & 326 & 0.7 & 3.2 & 1.5 & 1.2 & I.I & 0.8 \\
\hline Prilocaine & 1960 & 302 & 0.7 & 3.8 & 4.0 & 3.3 & 2.2 & 2.2 \\
\hline Tetracaine & 1932 & 245 & 0.5 & 2.5 & 3.0 & 2.1 & 1.4 & I.I \\
\hline Mepivacaine & 1957 & 211 & 0.5 & 2.2 & 2.4 & 2.4 & 2.0 & 1.4 \\
\hline Benzocaine & 1902 & 170 & 0.4 & 0.4 & 0.6 & 0.9 & 0.5 & 0.5 \\
\hline
\end{tabular}

Notes: Only anesthetics with 2009-20I3 GPI $\geq 0.1$ are included. Xenon and chloroprocaine did not reach this threshold. a As indicated in Miller's Anesthesia or Cousin's and Bridenbaugh's Neural Blockade. 'GPI share of all articles on anesthetics (Anesthetics [MeSH term]) published in 2009-20I3. 'SPI share of all articles on one of the following types of anesthesia: inhalational anesthesia (Anesthesia, Inhalation [MeSH term]), intravenous anesthesia (Anesthesia, Intravenous [MeSH term]), or local anesthesia

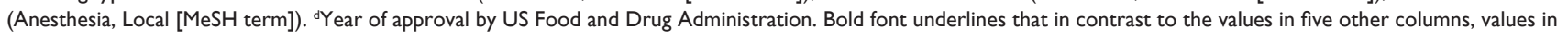
this column represent different type of calculations: shear of articles on anesthetics, not share of articles on appropriate type of anesthesia.

Abbreviations: GPI, general popularity index; SPI, specific popularity index. 


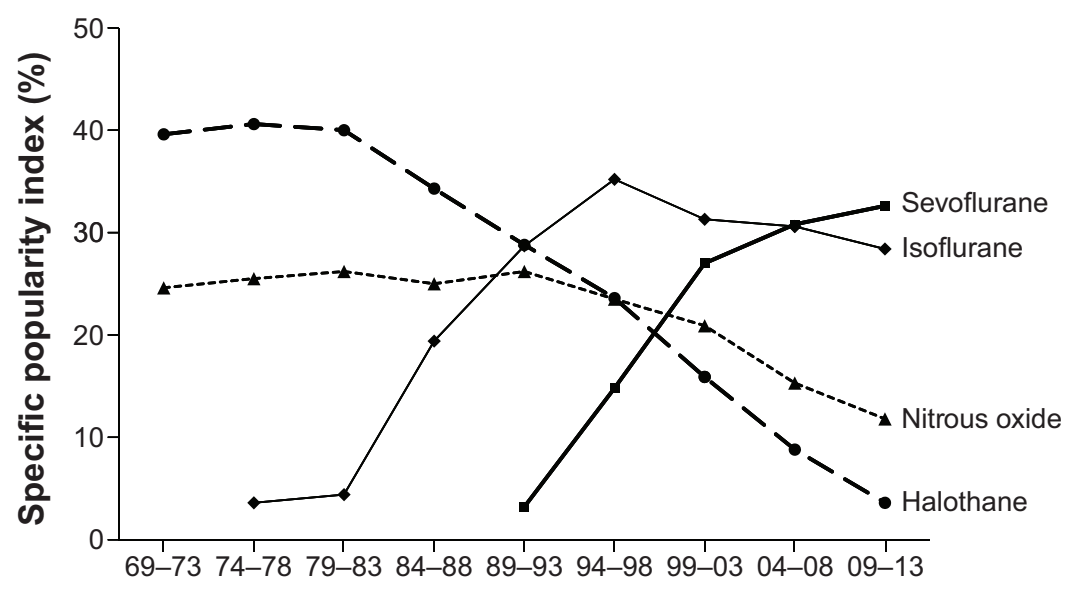

Five-year periods

Figure I Time course of specific popularity index for inhaled anesthetics: sevoflurane, isoflurane nitrous oxide, and halothane. The specific popularity index represents the share (percentage) of articles on an anesthetic relative to all articles on inhalational anesthesia during a 5-year period.

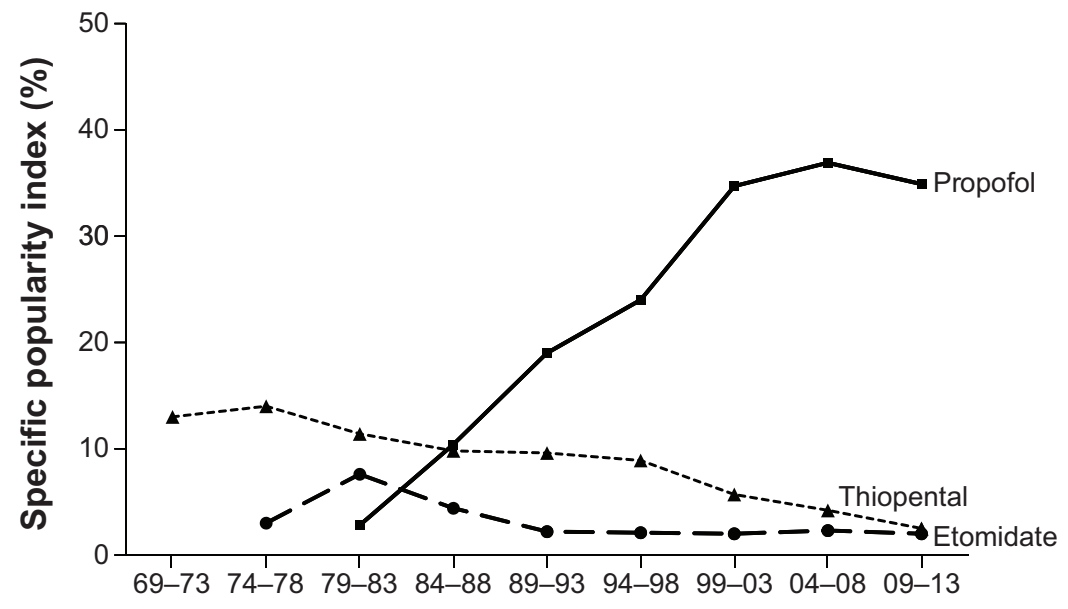

Five-year periods

Figure 2 Time course of specific popularity index for intravenous anesthetics: propofol, thiopental, and etomidate. The specific popularity index represents the share (percentage) of articles on an anesthetic relative to all articles on intravenous anesthesia during a 5 -year period.

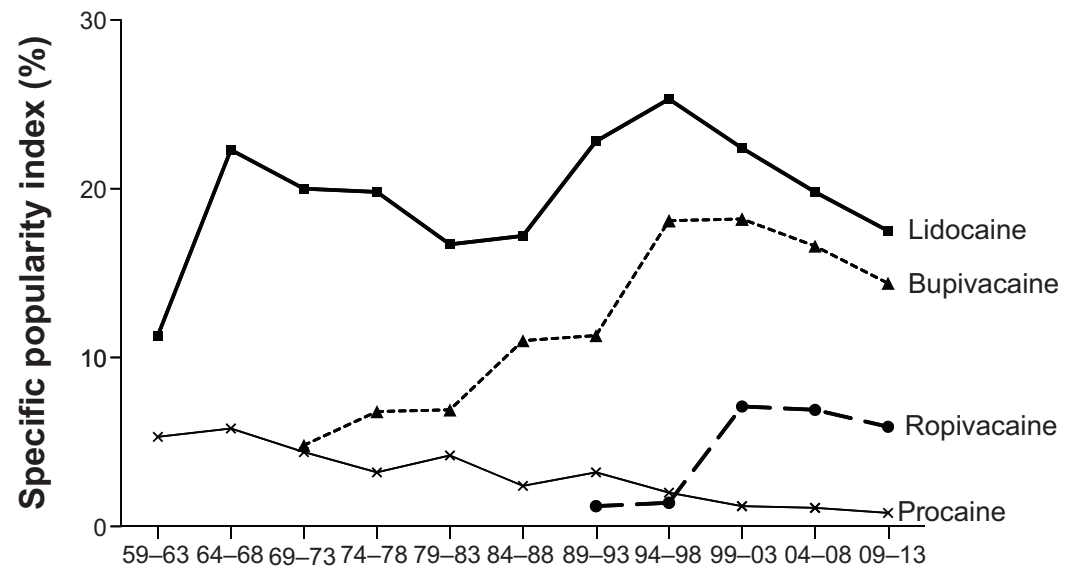

Five-year periods

Figure 3 Time course of specific popularity index for local anesthetics: lidocaine, bupivacaine, ropivacaine, and procaine. The specific popularity index represents the share (percentage) of articles on an anesthetic relative to all articles on local anesthetics during a 5-year period. 
The SPI indices are presented in Table 1 (right side) and in Figures 1-3. They indicate that changes in the popularity of anesthetics are usually very slow, with some having high SPIs for a very long time. For example, for the past 40-50 years, the SPI of lidocaine was amazingly stable at 22 in both 1964-1968 and 1999-2003, then there was a slight decline to 18 (2009-2013). Nitrous oxide was also highly popular for a long time; however, its popularity has decreased over the past 10 years.

As indicated by Table 2, only five anesthetics met our criteria to measure IE and IC, ie, three general anesthetics (propofol, sevoflurane, and desflurane) and two local anesthetics (ropivacaine and levobupivacaine). In 2009 2013, only sevoflurane and desflurane had an IE higher than the specific threshold of 10 , indicating the persistence of high expectations for these agents. At the same time, in 2009-2013, the IC of all five of these drugs was rather low, probably indicating that interest in them has peaked. Table 3 presents the IUS for various anesthetic drugs; lidocaine, isoflurane (combined with sevoflurane), and propofol all reached 50\% 10-20 years after their introduction.

\section{Anesthetic adjuncts}

Anesthetic adjuncts are presented in Table 4. In 2009-2013, only three drugs demonstrated both impressive increases in interest (IC > 50) and high expectations (IE $>10$ ), ie, rocuronium, sugammadex (an agent for reversal of rocuroniuminduced neuromuscular block), and dexamethasone (when used as an adjunct to local anesthetics). However, only sugammadex had a very high IE (25.0).

\section{Techniques}

Table 5 shows that among the techniques used for anesthetic administration during 2009-2013, there was a high IE (>10) for target-controlled anesthesia (14.6), bispectral index (14.6), and entropy (20.8), the latter two being processed electroencephalogram techniques for monitoring depth of anesthesia. However, in 2009-2013, the IC for these terms did not reach the specific threshold level of 50. Ultrasound-guided block had very high levels of IC over all recent 5-year periods, indicating a dramatic increase in the use of the technique. At the same time, the IE for this technique was above the specific threshold level of 10 in 1999-2003 and in 2004-2008; however, in the most recent period (2009-2013), its IE had already declined to 6.9. During 2004-2008, continuous nerve block had high values for both IC and IE, but in 2009-2013 they fell below the specific threshold levels.

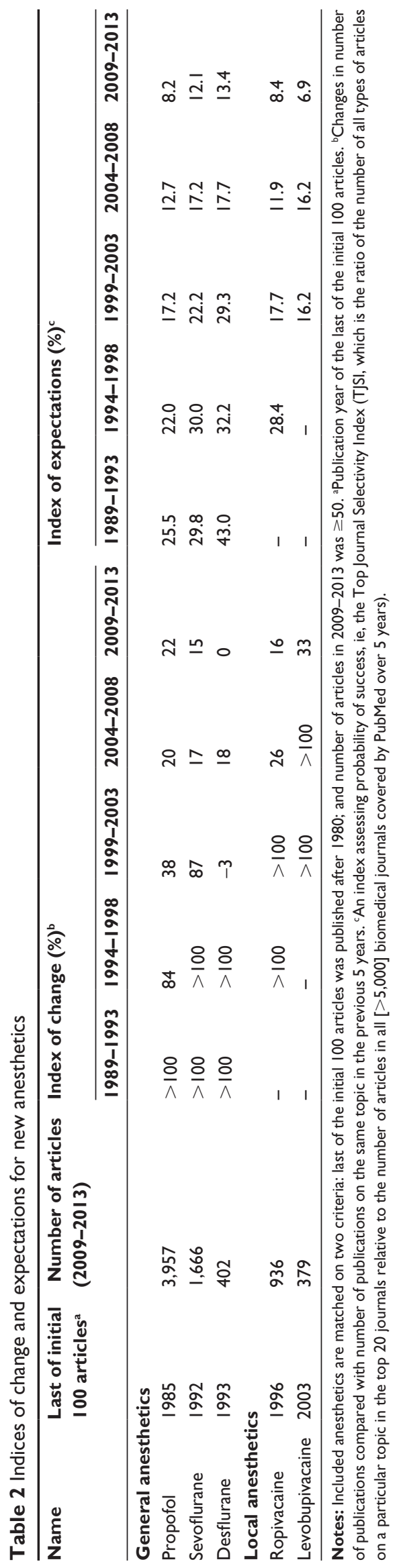




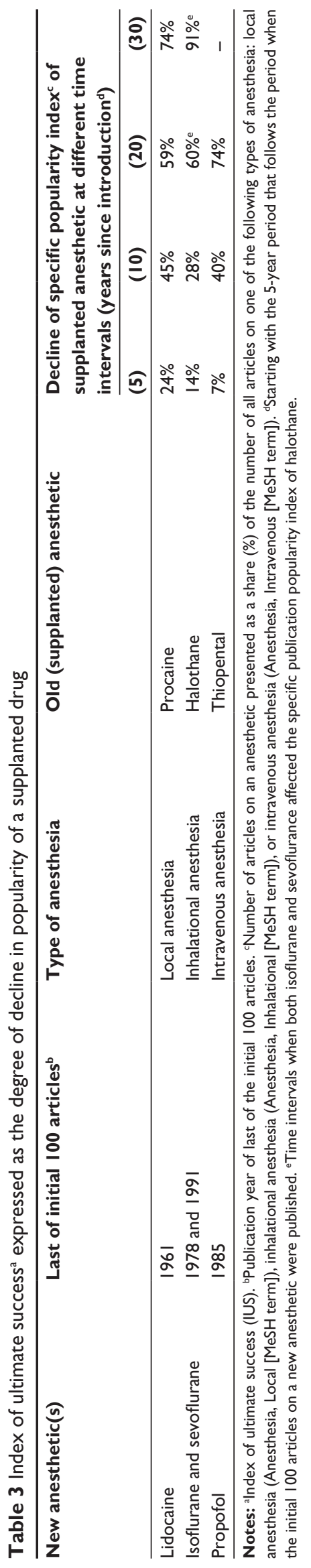

\section{Rate of publication growth}

The rates of 5-year publication growth for each of three classes of anesthetics (inhaled, intravenous, and local) are presented in Figure 4. In general, the most significant growth was with local anesthetics and the least significant was with inhaled anesthetics. In addition, the most obvious periods of growth for all classes of anesthetics were 1984-1988 and 1989-1993; however, for the past 20 years, growth was almost absent. This phenomenon is especially evident in Figure 5, which compares 10-year growth of publications on anesthetic-related articles with that of all PubMed drugrelated articles (entire pharmacology) and that of all articles related to anesthesia monitoring. In 2004-2013, only growth in articles on anesthesia monitoring was comparable with that of publications on all drugs in general.

\section{Discussion}

This is the first study that used specific scientometric indices to determine the evolution in use of anesthetics and to assess signs of progress in the field of anesthesia. It demonstrated that scientometric indices, suggested before ${ }^{1-6}$ and used in this study, can determine evolution of drugs through their presence in articles published in the academic journals. The results presented here indicate that over the past 30 years there were no new anesthetics that produced changes in scientometric indices indicating real progress. The dramatic decrease in anesthesia-related mortality is probably due not so much to the increased safety margins of new anesthetics, but to the improvements in safety rules related to their administration (eg, new anesthesia monitoring techniques and better anesthesiologists training).

\section{Anesthetics}

Our findings indicate that in 2009-2013 no anesthetics showed impressive increases in both IC and IE. Two recently introduced drugs, the local anesthetics ropivacaine and levobupivacaine, which previously demonstrated strong increases in IC and IE, had indices below specific threshold levels. For example, in 2009-2013, the IE levels for both drugs ( 8.4 for ropivacaine and 6.9 for levobupivacaine) did not indicate high expectations. In addition, their SPI (either in 1999-2003 or 2004-2008) did not begin high and did not increase in 2009-2013 (Table 1). Both drugs were developed based on experimental findings that systemic toxicity (mostly cardiotoxicity) of racemic bupivacaine was more pronounced with the R-enantiomer. As a result, the S-enantiomer preparations of ropivacaine and levobupivacaine were introduced to provide long-acting agents with greater safety margins. 


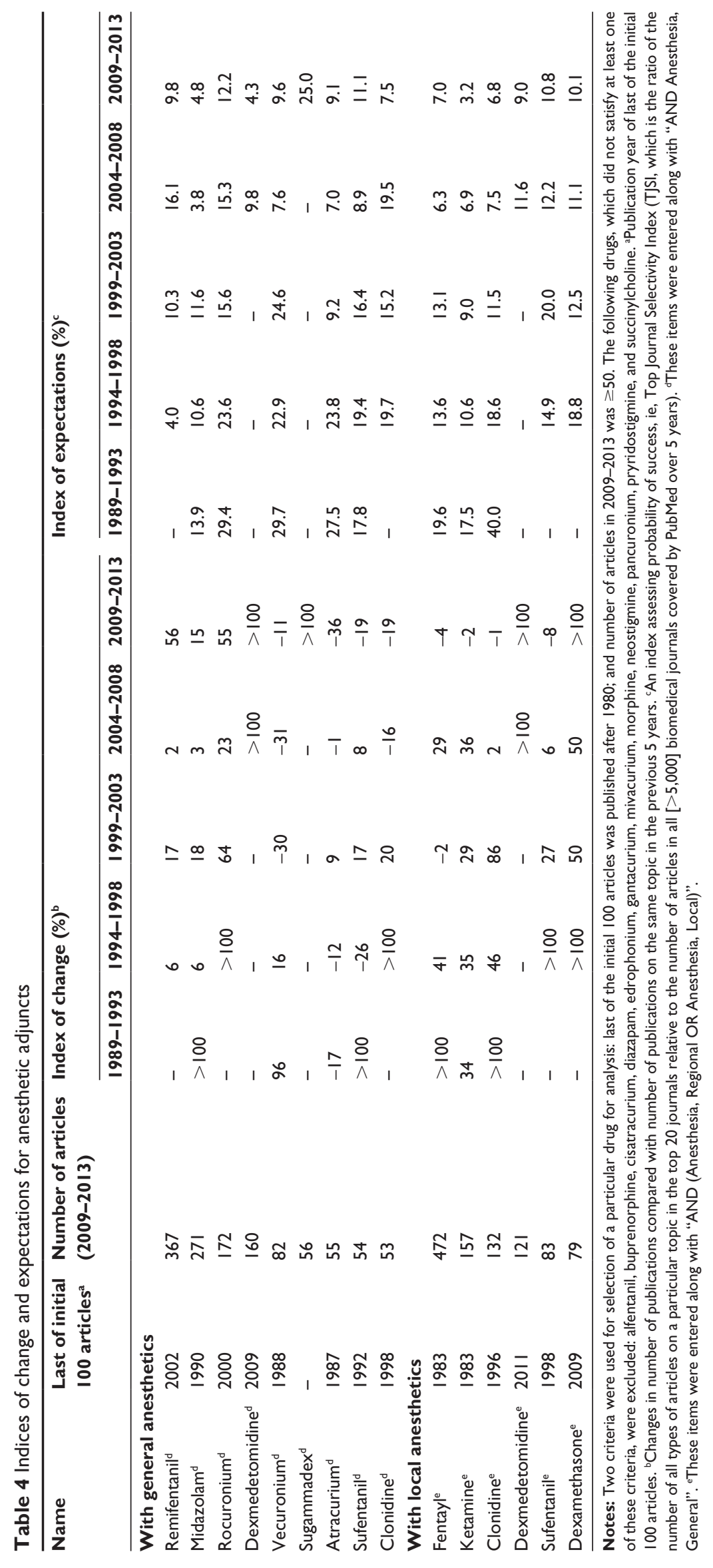




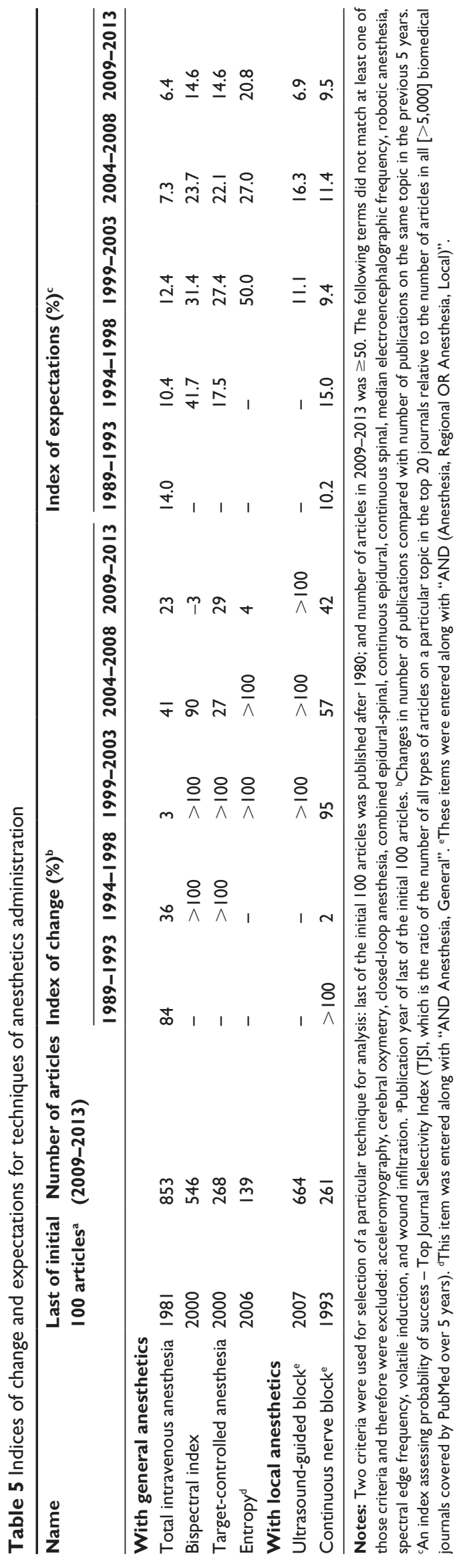

Despite the lack of good clinical evidence, but with the reliable results of experimental studies, the conclusion was made that ropivacaine is less cardiotoxic than other long-acting local anesthetics. ${ }^{21,22}$ Conclusions on the systemic toxicity of levobupivacaine seem to be less certain.

As far as general anesthetics are concerned, there were no dramatic increases in either IC or IE in 2009-2013; instead, only a steady decline of the very high indices following their introduction. The best example is desflurane, which was introduced in 1990. Its IC was very high in 1994-1998 but then plummeted to almost zero for the next 15 years (Table 2). The SPI of desflurane (Table 1) began to increase in 1994-1998, but remained static over the following 15-year period. This reflected a steep rise in the popularity of sevoflurane. The SPI of general anesthetics revealed the outcomes for another index that requires a long time to develop, ie, the IUS. As stated above, the most important outcome of the introduction of a new drug is the decline in the number of articles about another drug that previously dominated use for the same purpose. ${ }^{6}$ Figure 1 and Table 3 illustrate that isoflurane (in combination with sevoflurane) displaced halothane in medicobiological journals over the period of 30 years. Among the intravenous anesthetics, propofol had similar success (Figure 2 and Table 3), almost completely displacing thiopental. Among local anesthetics, lidocaine successfully supplanted procaine (Figure 3 and Table 3). As a result, it was not until 10-20 years after their introduction that the IUS of these anesthetics reached the level of 50 . After all, these agents were introduced long ago (lidocaine in 1947, isoflurane in 1971, and propofol in 1977).

\section{Anesthetic adjuncts}

Among the anesthetic adjuncts, only three drugs demonstrated increases above the specific threshold levels for both IC and IE, ie, rocuronium and sugammadex among general anesthetics, and dexamethasone with local anesthetics (Table 3). Rocuronium is a nondepolarizing neuromuscular blocking agent used to relax skeletal muscles without increasing the depth of anesthesia. Although it was introduced fairly long ago (in 1994), the increased interest in this drug seen in 2009-2013 is probably associated with successful development of sugammadex, an agent for the reversal of neuromuscular blockade induced by rocuronium (or other steroidal nondepolarizing agents) via a novel mechanism of action. ${ }^{23}$ The IC and IE for sugammadex (>100 and 25, respectively) indicate considerable interest and high expectations.

In 2009-2013, dexamethasone, used as an adjunct to local anesthetics, had values above the specific threshold 


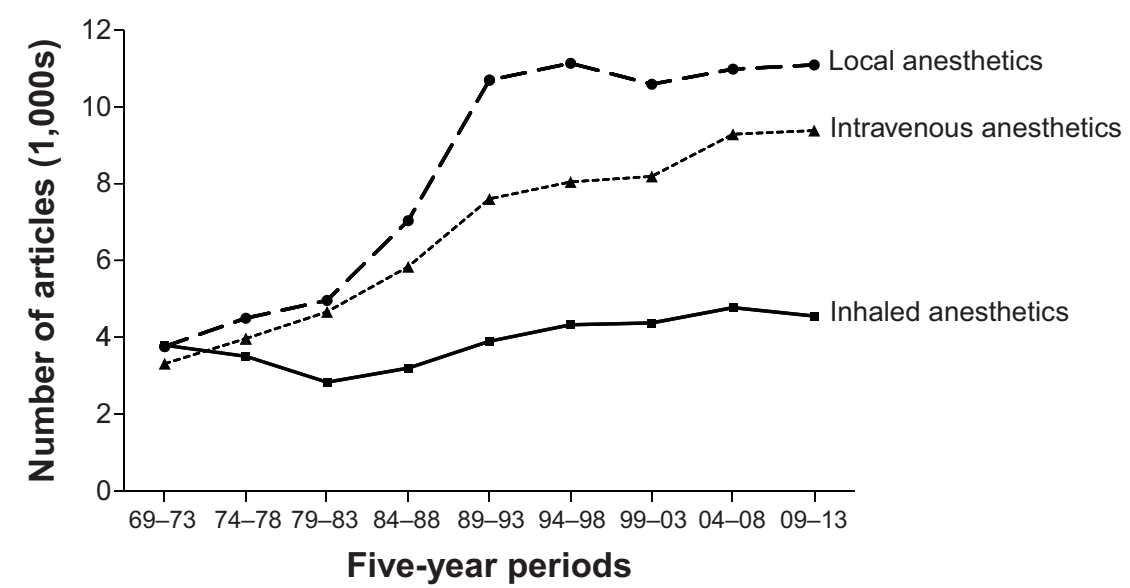

Figure 4 Five-year growth rates in the number of articles on inhaled, intravenous, and local anesthetics.

levels for both IC and IE (>100 and 10.1, respectively). These values are not significantly lower for dexmedetomidine ( $>100$ and 9.0 , respectively), which is primarily used as a sedative and intravenous coanesthetic. Coadministration of local anesthetics and $\alpha_{2}$ adrenergic agonists (clonidine or dexmedetomidine) or the corticosteroid dexamethasone provide ways to prolong peripheral nerve blockade without increasing the dose of local anesthetics and to avoid approaching the limits of the narrow therapeutic windows of local anesthetics. However, perineural administration has not yet been approved by the US Food and Drug Administration for either agent. Dexamethasone can be used (to prolong local anesthetic blockade and analgesia) perineurally or via systemic administration. Although its beneficial effect is thought to be mediated by attenuating the release of inflammatory mediators, several other properties of dexamethasone may also be important for this effect. ${ }^{24}$

\section{Techniques}

In 2009-2013, not a single technique demonstrated increases of both IC and IE above the specific threshold levels. The best results, although below these threshold levels in combination, were for target-control anesthesia (IC 29 and IE 14.6) and for continuous nerve block (IC 42 and IE 9.5). It should be noted that the increases in IC for ultrasound-guided block were above the specific threshold level for all 5 -year periods, starting with 1999-2003, indicating extremely high interest in the technique; however, IE was only 6.9 in 2009-2013. This technique completely supplanted (within a little more

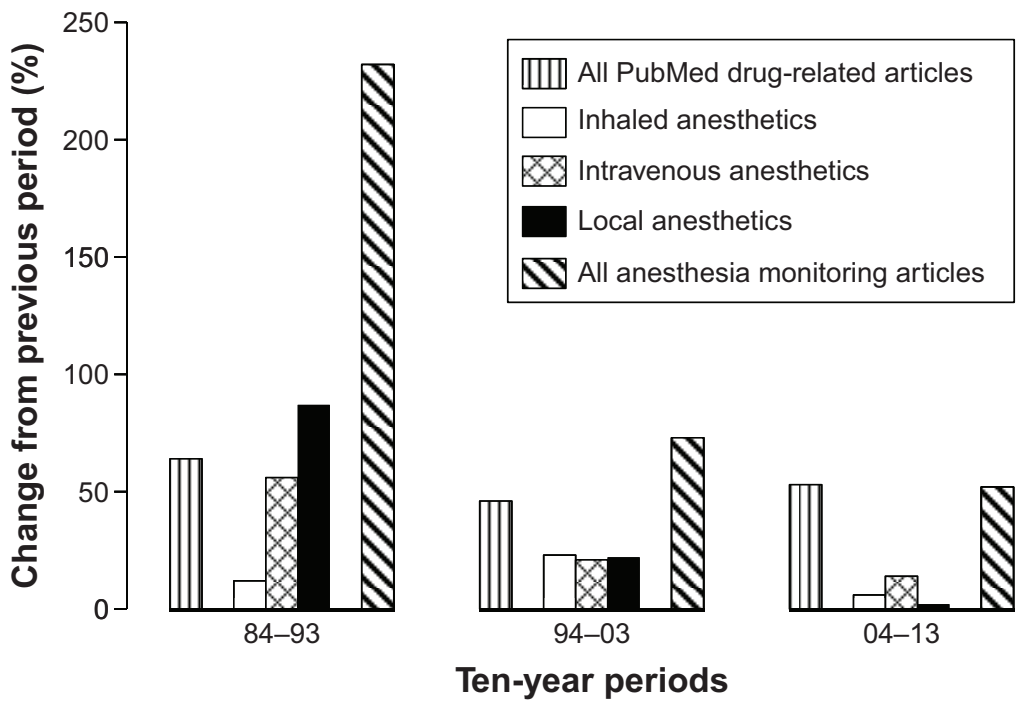

Figure 5 Comparative changes in 10-year growth rates in the number of articles on inhaled, intravenous, and local anesthetics versus all PubMed drug-related articles and anesthesia monitoring articles. 
than a decade) the previously used techniques of paresthesia and nerve stimulation for needle guidance.

The opposite combination of changes in both indices was observed with entropy (a processed electroencephalogram for monitoring depth of anesthesia): in 2009-2013, IE was high (20.8) and IC was low (4). A similar phenomenon was observed with another processed electroencephalogram, ie, bispectral index: although the IE was high for all 5-year periods since its introduction, including in 2009-2013 (14.6), the IC was very low (-3 in 2009-2013). The above results show high expectations related to techniques that measure and monitor the effect of general anesthetics. At the same time, one cannot exclude the role of extensive marketing for these techniques.

\section{Rate of publication growth}

The lack of success with new anesthetics coincides with declining rates of publication growth for all three types of agents, ie, inhaled, intravenous, and local. With inhaled anesthetics, growth was low during all three 10-year periods, 1984-1993, 1994-2003, and 2004-2013 (Figure 5). With intravenous and local anesthetics, the rate of growth in 1984-1993 was at the level of growth with all PubMed drug-related articles (close to 60\%); however, in the next two 10 -year periods it progressively declined to almost zero in 2004-2013. These declines were not a sign of the absence of research growth in anesthesia in general. The best example of growth is the research efforts in the field of anesthesia monitoring, which profoundly exceeded those in other drug-related fields during 1984-1993. During the two other 10-year periods (1994-2003 and 2004-2013), the growth in monitoring was on the level with growth among all PubMed drug-related articles.

\section{Margins of safety}

Margins of safety are very low with all classes of anesthetics, and major efforts to improve the safety margins of these agents have yielded sparse results. As indicated in the introduction, inhaled anesthetics have very low therapeutic indices, making them "among the most dangerous drugs in clinical use". ${ }^{13}$ This was the main reason for the high mortality and morbidity of general anesthesia. Substituting isoflurane and sevoflurane for halothane (Figure 1) likely improved the safety of anesthesia; for example, concerns regarding hepatic injury with inhalational anesthesia seem to have disappeared. Notably, the experimentally determined therapeutic index of isoflurane is better than that of halothane. In rats the $\mathrm{LD}_{50} / \mathrm{ED}_{50}$ index for motor responses with isoflurane is 1.7 times higher than with halothane. ${ }^{14}$ However, the margins of safety of inhaled anesthetics are still too low.

Therapeutic indices $\left(\mathrm{LD}_{50} / \mathrm{ED}_{50}\right)$ for intravenous anesthetics in general are not much better than those for inhaled anesthetics. However, the therapeutic index of intravenous anesthetics varies much more than that of inhaled anesthetics. For example, the $\mathrm{LD}_{50} / \mathrm{ED}_{50}$ index for motor responses in rats is 3.1 times higher with etomidate than with thiopental. ${ }^{25}$ The greater margin of safety in combination with good hemodynamic stability led to the initial widespread use of etomidate, especially in critically ill patients. However, one specific side effect, adrenocortical suppression, has tempered the enthusiasm of anesthesiologists for etomidate. Efforts are currently directed toward creation of an etomidate analog that offers the beneficial properties of this drug without significant adrenocortical suppression. ${ }^{26}$

Local anesthetics, if used in large doses to produce epidural anesthesia or blockade of peripheral nerves, also pose the problem of low margins of safety, but to a lesser degree than general anesthetics. Similarly, reported mortality seems to be lower with regional anesthesia than with general anesthesia, according to some studies by about a third..$^{27,28}$

Insufficient progress in finding new anesthetics with appreciably better margins of safety has led anesthesiologists to redouble their efforts to compensate for this drawback. This work has developed along two basic directions, ie, better training of anesthesia providers and improvements in the technology of anesthesia monitoring. The first direction produced the present situation: a physician with 3 years of anesthesia residency training, or a closely supervised nurse anesthetist, usually gives minute-by-minute undivided attention to the status of each anesthetized patient. The other direction has produced various techniques for patient monitoring, such as oximetry, capnography, quantitative neuromuscular blockade monitoring, and processed electroencephalography monitoring, many of which have become standard worldwide. As a result of improved vigilance ("vigilance" has been the motto of the American Society of Anesthesiologists), anesthesiology reached an exceptional position among the branches of medicine and became a model for patient safety. ${ }^{29}$ Therefore it is possible that the decrease in anesthesia-related mortality over the past 30-40 years (approximately 10-fold lower compared with 1954-1975) was not produced by the development of anesthetics with better margins of safety, but mostly by improved vigilance while using anesthetics with low margins of safety.

The scientometric indices used to identify signs of progress in the therapeutics (GPI, SPI, IC, IE, and IUS) are 
based on the link between the number of publications and the progress in pharmacotherapy. However, this link is inherently weak. This weakness is underlined by the fact that the mere number of publications does not differentiate between publications characterizing a drug in a positive or negative way. Therefore, scientometric indices should be assessed in combination with results on drug effectiveness based on good quality evidence. The indices used here have different degrees of reliability in demonstrating a drug's progress: from the lower levels with GPI, SPI, IC, and IE to a higher level with IUS.

\section{Disclosure}

The authors report no conflicts of interest in this work.

\section{References}

1. Kissin I. Can a bibliometric indicator predict the success of a drug? Scientometrics. 2011;86:785-795.

2. Kissin I, Bradley EL Jr. Top Journals Selectivity Index: is it acceptable for drugs beyond the field of analgesia? Scientometrics. 2011;88: 589-597.

3. Kissin I, Bradley EL Jr. Top Journal Selectivity Index and 'me-too' drugs. Scientometrics. 2012;91:131-142.

4. Kissin I. An early indicator of drug success: Top Journal Selectivity Index. Drug Des Devel Ther. 2013;7:93-98.

5. Correll DJ, Vlassakov KV, Kissin I. No evidence of real progress in treatment of acute pain, 1993-2012: scientometric analysis. J Pain Res. 2014;7:199-210.

6. Kissin I. Scientometric assessment of drugs for chronic pain, 19792013: rapid growth of publications, paucity of successful drugs. J Pain Res. 2014;7:505-514.

7. Beecher HK, Todd DP. A study of deaths associated with anesthesia and surgery. Ann Surg. 1954;140:2-34.

8. Dornette WH, Orth OC. Death in the operating room. Curr Res Anesth Analg. 1956;545-569.

9. Memery HN. Anesthesia mortality in private practice. A ten-year study. JAMA. 1965;194:1185-1188.

10. Marx GF, Mateo CV, Orkin LR. Computer analysis of postanesthetic deaths. Anesthesiology. 1973;39:54-58.

11. Bodlander FM. Deaths associated with anaesthesia. Br J Anaesth. 1975; 47:36-40.

12. Fleisher LA. Risk of anesthesia. In: Miller RD, Eriksson LI, Fleisher L, Wiener-Kronish JP, Young WL, editors. Miller's Anesthesia. 7th ed. Philadelphia, PA, USA: Churchill Livingstone; 2010.
13. Patel PM, Patel HH, Roth DM. General anesthetics and therapeutic gases. In: Brunton L, Chabner BA, Knollmann BC, editors. Goodman \& Gilman's Pharmacological Basis of Therapeutics. 12th ed. New York, NY, USA: McGraw-Hill; 2011.

14. Kissin I, Morgan PL, Smith LR. Comparison of isoflurane and halothane safety margins in rats. Anesthesiology. 1983;58:556-561.

15. Miller RD, Eriksson LI, Fleisher L, Wiener-Kronish JP, Young WL, editors. Miller's Anesthesia. 7th ed. Philadelphia, PA, USA: Churchill Livingstone; 2010.

16. Evers AS, Maxe M, Kharasch ED, editors. Anesthetic Pharmacology, 2nd ed. Cambridge, UK: Cambridge University Press; 2010.

17. Cousins MJ, Carr DB, Horlocker T, Bridenbaugh PO, editors. Cousins \& Bridenbaugh's Neural Blockade in Clinical Anesthesia and Pain Medicine. 4th ed. Philadelphia, PA, USA: Wolters Kluwer; 2009.

18. Fishman SM, Ballantyne JC, Rathmell JP, editors. Bonica's Management of Pain. 4th ed. Philadelphia, PA, USA: Wolters Kluwer/Lippincott Williams \& Wilkins; 2010.

19. Brunton L, Chabner BA, Knollmann BC, editors. Goodman \& Gilman's Pharmacological Basis of Therapeutics. 12th ed. New York, NY, USA: McGraw Hill Medical; 2011.

20. American Pharmacists Association. Drug Information Handbook. 22nd ed. Hudson, OH, USA: Wolters Kluwer; 2013.

21. Berde CB, Strichartz GR. Local anesthetics. In: Miller RD, Eriksson LI, Fleisher L, Wiener-Kronish JP, Young WL, editors. Miller's Anesthesia. 7th ed. Philadelphia, PA, USA: Churchill Livingstone; 2010.

22. Zink W, Graf BM. Toxicity of local anesthetics: the place of ropivacaine and levobupivacaine. Curr Open Anesthesiol. 2008;21:645-650.

23. Puhringer FK, Gordon M, Demeyer I, et al. Sugammadex rapidly reverses moderate rocuronium- or vecuronium-induced neuromuscular block during sevoflurane anesthesia: a dose-response relationship. Br J Anaesth. 2010;105:610-619.

24. Choi S, Rodseth R, McCartney CJ. Effects of dexamethasone as a local anesthetic adjuvant for brachial plexus block: a systematic review and meta-analysis of randomized trials. Br J Anaesth. 2014;112:427-439.

25. Kissin I, McGee T, Smith LR. The indices of potency for intravenous anesthetics. Can Anaesth Soc J. 1981;28:585-590.

26. Cotten JF, Forman SA, Laha JK, et al. Carboetomidate: a pyrrole analog of etomidate designed not to suppress adreno-cortical function. Anesthesiology. 2010;112:637-644.

27. Bulka CM, Shotwell MS, Gupta RK, Sandberg WS, Ehrenfeld JM. Regional anesthesia, time to hospital discharge and in-hospital mortality: a propensity score matched analysis. Reg Anesth Pain Med. 2014;39: 381-386.

28. Rodgers A, Walker N, Schug S, et al. Reduction of postoperative mortality and morbidity with epidural or spinal anaesthesia: results from overview of randomized trials. $B M J$. 2000;321:1493.

29. Cooper JB, Gaba D. No myth: anesthesia is a model for addressing patient safety. Anesthesiology. 2002;97:1335-1337.
Drug Design, Development and Therapy

\section{Publish your work in this journal}

Drug Design, Development and Therapy is an international, peerreviewed open-access journal that spans the spectrum of drug design and development through to clinical applications. Clinical outcomes, patient safety, and programs for the development and effective, safe, and sustained use of medicines are a feature of the journal, which

\section{Dovepress}

has also been accepted for indexing on PubMed Central. The manuscript management system is completely online and includes a very quick and fair peer-review system, which is all easy to use. Visit http://www.dovepress.com/testimonials.php to read real quotes from published authors. 